\title{
A Majority of Admitted Patients With Ruptured Abdominal Aortic Aneurysm Undergo and Survive Corrective Treatment: A Population-Based Retrospective Cohort Study
}

\author{
R. Hultgren ${ }^{1,2}$ (D) Sayid Zommorodi ${ }^{3} \cdot$ Moa Gambe $^{1} \cdot$ Joy $^{\text {Roy }}{ }^{1,2}$
}

Published online: 22 August 2016

(c) The Author(s) 2016. This article is published with open access at Springerlink.com

\begin{abstract}
Background Abdominal aortic aneurysm (AAA) is an asymptomatic, potentially lethal condition predominantly found in elderly. The mortality is $100 \%$ if rupture occurs and left untreated, but even in treated patients the mortality is substantial. Female sex and treatment with open repair rather than endovascular aortic repair (EVAR) have been reported to negatively affect outcome. The objective was to describe the contemporary care and outcome of all treated and untreated patients with ruptured AAA (rAAA) admitted to hospital.

Method Population-based retrospective investigation, including all patients admitted to the emergency departments within Stockholm County diagnosed with rAAA 2009-2013. All identified patients' charts $(n=297)$ were analyzed; the study cohort includes 283 verified patients.

Results Men were in majority [214 (76\%), 69 (24\%) women] and were younger than women (78 vs 82 years, $p<0.001)$. A majority of patients were treated $(212 / 283,75 \%)$, a similar proportion of women and men. Untreated patients had a higher mean age ( 84 vs 77 years, $p<0.001)$. The proportion treated with EVAR was $27 \%$, and they were older than OR treated ( 79 vs 76 years, $p=0.043$ ). Forty-seven percentage of patients admitted with rAAA survived 30 days, and $62 \%$ of treated patients survived 30 days. The 30-day mortality for women and men was similar.

Conclusions Our results and other contemporary series show a shift toward a higher rate of treated patients with rAAA, and improving outcomes, similar for women and men. The increased use of EVAR contributes to this improvement in short-term outcome. High age influences the willingness to treat patients with rAAA.
\end{abstract}

Our original work has been approved by all authors, and all authors accept full responsibility for the design and conduct of the study, had access to the data, and controlled the decision to publish. This work has not been published previously and is not under consideration for publication elsewhere.

Moa Gambe: Medical Student at the Department when collecting data.

R. Hultgren

rebecka.hultgren@karolinska.se

1 Department of Molecular Medicine and Surgery, Karolinska Institutet, Stockholm, Sweden

\section{Introduction}

Abdominal aortic aneurysm (AAA) is an asymptomatic, not uncommon and potentially lethal condition predominantly found in persons above 50 years of age. Patients with ruptured AAA, left untreated, have a $100 \%$ fatality rate. The mortality is substantial even in treated patients

2 Department of Vascular Surgery A2:01, Karolinska University Hospital, Stockholm, Sweden

3 Section for Vascular Surgery, Department of Surgery, Södersjukhuset, Stockholm, Sweden 


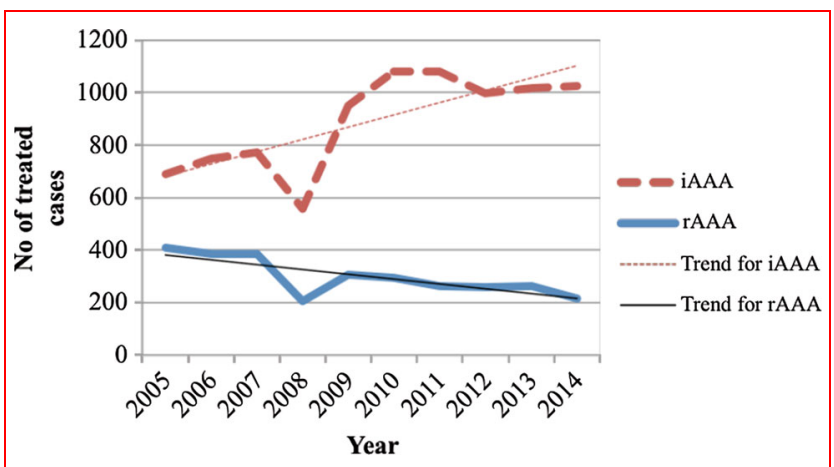

Fig. 1 Annual number of elective and ruptured patients treated in Sweden 2005-2013, from SWEDVASC, changes in the Web-based program was performed in 2008, which influences the number of all registered cases

with ruptured AAA (rAAA), ranging from 20 to $60 \%$ [1-3]. Interestingly, both AAA prevalence and the number of patients treated for rAAA have declined the past 20 years; such a trend is reported in the Swedish national registry parallel to an increment of elective repair (Fig. 1) $[1,3,4]$. A further decline is expected due to the population-based screening program for AAA in elderly men introduced in our region $[1,3,5-8]$.

Most studies have focused only on the treated patients, and historically only a few studies have addressed and included the persons admitted but left untreated, which indeed does affect the view on patient care of this group [2, 9-11]. Treated women, both in series of ruptured and elective cases, have been reported to have a worse outcome than men. This can correlate with their higher age when treated, poorer morphology or different distribution of risk factors $[1,12-16]$ A risk of withholding corrective treatment in women with rupture compared to men has been described: $73 \%$ of men treated versus $56 \%$ of women, also confirmed in a single-center study from Australia (fewer women were treated 37 vs $63 \%$ ) [17]. The strongest predictor for death due to most surgical procedures, as well as rAAA, is old age $[1,12,18-22]$. It is not certain how influential the patient's age is on the decision to offer corrective treatment to rAAA patients. Mortality is higher after OR than EVAR according to retrospective studies $[12,21,23,24]$, and this is also reported in the Swedish Vascular Registry [3]. EVAR is a less invasive method than OR, with a lower perioperative complication rate, but randomized trials have failed to show a difference in shortterm mortality [25-27].

The objective with this population-based investigation was to report differences in the contemporary care of all treated and untreated patients with rAAA admitted to a hospital with special consideration of age and gender.
Materials and methods

\section{Study population and settings}

There are two centralized vascular departments serving the county with emergency and elective vascular care: Karolinska University Hospital and Stockholm South General Hospital (Södersjukhuset), which together cover $20 \%$ of the Swedish population, including care of patients on the Island of Gotland. Patients operated outside of Stockholm County were excluded from this analysis.

All patients admitted to the emergency departments of the seven county hospitals within Stockholm County and Island of Gotland, and diagnosed with rAAA according to revision 10 of the International Classification of Diseases (ICD 10: I71.3) from January 2009 to December 2013 were identified. All hospitals have electronic daily updated chart systems, and the healthcare system is based on a delivery of the patients' care (date for hospital stay, diagnosis, operations and the unique personal number of each inhabitant) which will then allow reimbursement to the hospital accordingly. This financial hospital system minimizes events of care that are unregistered. Surgery, medicine, cardiology and emergency departments were included in the requisition, to minimize missing rAAA patients admitted at other departments.

\section{Data collection}

All identified patients admitted to the hospitals were identified by their unique personal identity numbers at each hospital $(n=297)$. Twelve patients were excluded; because of previous aortic surgery $(n=10)$ and mycotic rAAA $(n=2)$. Two patients could not be identified due to invalid personal registration numbers.

\section{Definitions}

AAA was defined as an aneurysm with an infra-renal proximal limit. rAAA was verified as the diagnosis mentioned explicitly in medical records, with typical rupture verified by radiology or at intervention, or in an autopsy report. Hospital stay and ICU stay were calculated from date of admittance and date of discharge. AAA diameter was defined as the largest diameter of the ruptured aneurysm on CT or ultrasound. Type of surgery was defined as either OR or EVAR. The group definition "Cardiac disease" includes: former or current heart failure, angina pectoris, myocardial infarction or arrhythmia mentioned in medical records. Smoking was defined as past or current smoking, from medical records. Preoperative mortality was defined as death before start of operation. Perioperative 
Fig. 2 All admitted patients with rAAA, and mortality within 30 days for all women and men during 2009-2013. Red boxes show surviving patients, gray boxes show the deceased. *percent of treated cohort, $n=212$

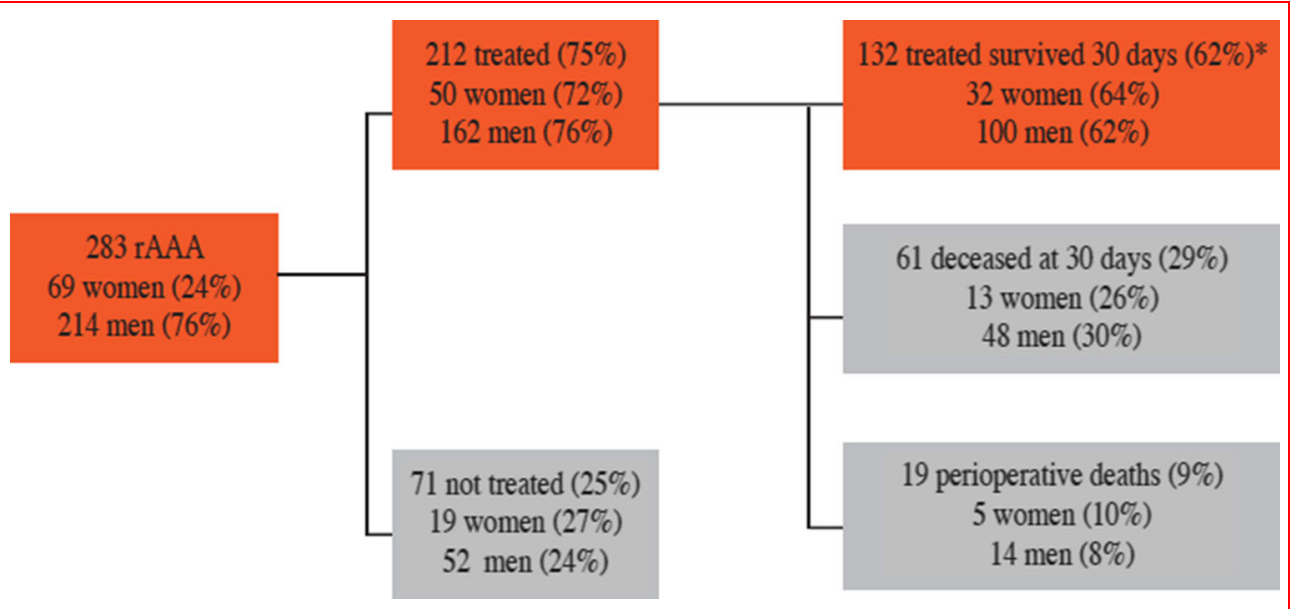

Table 1 Characteristics, treatment and outcome variables for all included women and men

\begin{tabular}{|c|c|c|c|}
\hline Variable & $\begin{array}{l}\text { Men } \\
n=214\end{array}$ & $\begin{array}{l}\text { Women } \\
n=69\end{array}$ & $p$ \\
\hline Age (years) & $77.56 \pm 9.26$ & $82.14 \pm 6.57$ & $<0.001$ \\
\hline $\mathrm{BMI}^{\mathrm{b}}$ & $28.4(16.8)$ & $22.4(2.9)$ & 0.002 \\
\hline AAA diameter $(\mathrm{mm})^{\mathrm{d}}$ & $82.7 \pm 20.23$ & $73.6 \pm 15.98$ & 0.006 \\
\hline Previously known AAA & $58(27.1)$ & $27(39.1)$ & 0.058 \\
\hline Hypertension & $126(58.9)$ & 49 (71.6) & 0.19 \\
\hline Diabetes mellitus & $27(12.6)$ & 8 (11.6) & 0.961 \\
\hline COPD & $27(.12 .6)$ & $15(21.7)$ & 0.18 \\
\hline Cardiac disease & $81(37.9)$ & $21(30.4)$ & 0.475 \\
\hline Ever smoker ${ }^{\mathrm{a}}$ & $82 / 110(74.5)$ & 24/34 (70.6) & 0.752 \\
\hline Pre-op creatinine ${ }^{\mathrm{c}}$ & $121.4(51.4)$ & $107.8(42.4)$ & 0.089 \\
\hline Operation rate & $162(75.7)$ & $50(72.4)$ & 0.625 \\
\hline ICU stay all (days) & $4.38(7.77)$ & $3.27(6.05)$ & 0.287 \\
\hline 30-Day mortality all admitted & $114(53)$ & $37(54)$ & 0.756 \\
\hline Treated & 162 men & 50 women & \\
\hline Mean age & $75.7(8.68)$ & $80.7(6.15)$ & $<0.001$ \\
\hline EVAR rate (\% of operated) & $41(25.3)$ & $17(34.0)$ & 0.511 \\
\hline Hospital stay (days) for treated & $13.7(18.2)$ & $11.3(10.5)$ & 0.245 \\
\hline ICU stay (days) & $5.80(8.52)$ & $4.57(6.05)$ & 0.278 \\
\hline Perioperative mortality & $14(8.9)$ & $5(10.4)$ & 0.815 \\
\hline 30-Day mortality all treated & $62(38)$ & $18(36)$ & 0.860 \\
\hline
\end{tabular}

Presented as numbers (\%) and mean (standard deviation)

${ }^{a}$ Missing cases: 35 women and 104 men, classified as unknown smoking history, ${ }^{\mathrm{b}} \mathrm{kg} / \mathrm{m} \mathrm{2}$, ${ }^{\mathrm{c}}$ micromol/1

d According to primary assessment by radiologist (134 missing assessments)

mortality was defined as death during operation, including anesthesia. 30-day mortality included perioperative and postoperative death within 30 days after surgery. There were some missing values, such as smoking habits, which contribute to lower numbers in the presented tables. Height and weight were used to calculate body mass index (BMI).

\section{Statistics}

Continuous variables, with a normal distribution (age, AAA diameter and anthropometrical variables), are presented as mean \pm standard deviation (SD). Normal distribution of continuous variables was tested according to 


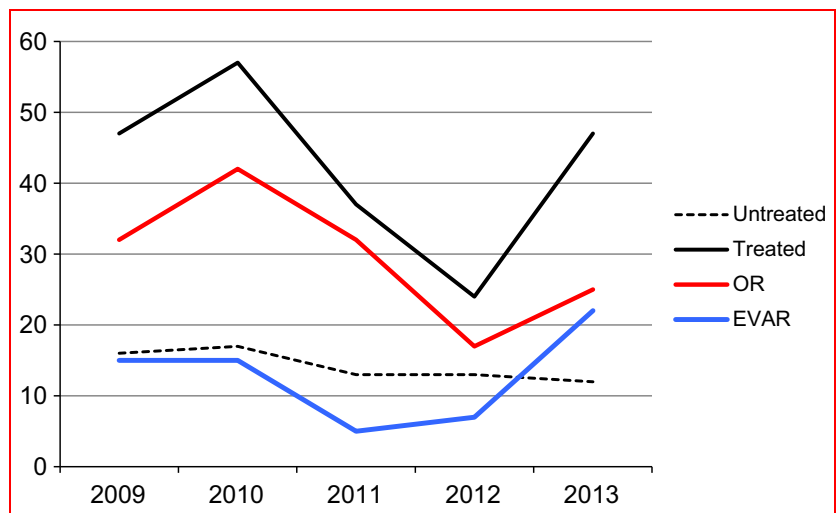

Fig. 3 Annual number of untreated and treated patients, and the number of treated patients with EVAR or OR 2009-2013

Shapiro-Wilk's, where $p>0.05$ indicates normality; independent $t$ test was used for continuous variables. Categorical values were presented as absolute numbers and percentages. Pearson's Chi-square test was used for categorical variables. SPSS ${ }^{\circledR}$ version $22\left(\right.$ IBM $^{\circledR}$, Armonk, New York, US) was used for statistical analysis and calculation. Level of significance was set at $p \leq 0.05$.

\section{Ethical permission and reporting}

The study was approved by the Regional Ethical Review Board in Stockholm. Registration number: 2013/1277-31/ 3 . The reporting of this study conforms to the Strengthening the Reporting of Observational Studies in Epidemiology (STROBE) statement [28].

\section{Results}

\section{Patient characteristics}

The study cohort is based on 283 patients diagnosed with rAAA, $214(76 \%)$ men and $69(24 \%)$ women (Fig. 2; Table 1 ). Women were older (82 vs 78 years, $p<0.001$ ) compared to men (Table 1). The distribution between the age groups was different for women and men, and a majority of women were older than 80 as compared to men (69 vs $48 \%$, $p=0.005$ ). The youngest woman was 67 years, the youngest man was 48 , and 20 men were admitted with rAAA below 65 years of age ( $9 \%$ of all men). Men had higher body mass index and creatinine clearance as compared to women; most other comorbid conditions were similar. The ICU stay for patients admitted after treatment was similar for women and men, and the mean stay was 4 days (Table 1).

Mortality rates (preoperative, perioperative, postoperative) were similar in men and women, even though women were 4.5 years older (Table 1). Overall, $47 \%$ of patients admitted to hospital with rAAA will survive 30 days, and $62 \%$ of patients subjected to treatment will survive 30 days (Table 1; Fig. 2).

\section{Treatment and outcome}

\section{Treated}

The intervention rates were similar in women and men ( 72 vs $76 \%, p=0.625$; Table 1). The treated women had a higher mean age than treated men (Table 1). Among the treated patients, men had a trend toward a higher prevalence of

Table 2 Treated with EVAR versus OR

\begin{tabular}{|c|c|c|c|}
\hline Variable & $\begin{array}{l}\mathrm{OR} \\
N=154\end{array}$ & $\begin{array}{l}\text { EVAR } \\
N=58\end{array}$ & $p$ \\
\hline Mean age (SD) & $76.2(7.96)$ & $78.8(9.34)$ & 0.043 \\
\hline Previously detected & $36(23)$ & $14(24)$ & 0.907 \\
\hline Women & $33(21)$ & $17(29)$ & 0.223 \\
\hline Hypertension & $99(64)$ & $34(59)$ & 0.45 \\
\hline Heart disease & $52(34)$ & $20(34)$ & 0.63 \\
\hline COPD & $18(12)$ & $13(22)$ & 0.117 \\
\hline Creatinine & $115.4(44.0)$ & $126.5(63.3)$ & 0.26 \\
\hline Blood pressure, lowest before ${ }^{a}$ & $74.12(41.1)$ & $96.30(39.1)$ & $<0.001$ \\
\hline ICU stay (days) & $6.3(8.81)$ & $3.49(4.93)$ & 0.006 \\
\hline Hospital stay & $14.3(18.6)$ & $10.1(9.67)$ & 0.036 \\
\hline Perioperative mortality & $18(11.7)$ & $1(1.7)$ & 0.024 \\
\hline 30-Day mortality all treated & $72(46.8)$ & $8(13.8)$ & 0.001 \\
\hline
\end{tabular}

Presented as numbers (\%) and mean (standard deviation)

${ }^{\text {a }}$ Missing cases: 30 patients 
cardiac disease than women [61/162 (38 \%) vs 11/50 (22\%) in women, $p=0.07]$. Diabetes, hypertension and COPD were similarly distributed (data not shown).

The proportion of patients treated with EVAR was $27 \%$, similar for women and men (34 vs $25 \%, p=0.51$; Table 1). The use of EVAR increased during the later observed time period (Fig. 3). The EVAR-treated patients were older than OR-treated patients ( 79 vs 76 years, $p=0.043$; Table 2 ). The comorbidity profile was similar between the groups (Table 2). The lowest preoperative systolic BP was found in the OR group.

The postoperative care was prolonged in OR patients (longer ICU, hospital stay), and they had a higher perioperative and 30-day mortality than EVAR treated (Table 2). The 30-day mortality for treated women and men was similar (13/50 vs 48/162, $29 \%, p=0.961$; Table 1$)$.

\section{Untreated}

A majority of patients admitted to the ER with rAAA were treated $(212 / 283,75 \%)$. The mortality among patients who were not operated was $100 \%$. The untreated patients had a higher mean age than treated [84 (SD 8.20) vs 77 (SD 8.42) years, $p<0.001$; Table 3]. There was a similar proportion of men and women in the untreated group $(p=0.63$; Table 1; Fig. 2). A higher proportion of the untreated patients had a previously diagnosed AAA (35/71 vs $50 / 212, p<0.001)$. The age difference between women and men is smaller in the untreated group compared to the treated ( 85.8 vs 83.2 years for untreated and 80.7 vs 75.7 years in treated, $p<0.001$ ).

\section{Discussion}

This contemporary series on rAAA patients shows that $75 \%$ of rAAA patients admitted to a hospital are treated, and the survival rate among the treated patients is better than reported in older series. There is also a lack of gender differences in crude operation rates or outcome when analyzing all patients admitted with rAAA, although women were considerably older than men. Several recent publications have reported on similar rates of untreated as ours, $25 \%$ and also a lack of gender differences. A better immediate outcome is found in patients treated with EVAR rather than OR.

Few series have historically included the untreated group; however, several recently published series have included them $[2,9,10,23]$. The report from the UK on rAAA has a similar proportion as Stockholm, $26 \%$ [2]. The recently published Finnish study based on data from 2001 to 2011 report $57 \%$ untreated, however, includes persons dying at home, before treatment is evaluated. Including only the patients admitted to hospital were included, their rate would be similar to ours $(25 \%, 70 / 281)$ [10] (Table 4). The recently published report on patients collected during 8 years, in the Netherlands on "treated versus untreated," is difficult to interpret and has a parallel ongoing bias for inclusion into the Ajax trial [11]. The Norwegian study covering 2000-2013, on 216 patients, has quite similar data [9] (Table 4). The older, often cited autopsy-based report from Malmö had a higher rate of untreated [29]. Probably, we have a shift in the care of rAAA and AAA patients, and a more positive attitude toward treating more diseased patients. The better immediate results of EVAR versus OR could also contribute $[18,23,30]$.

Age has always been reported to be an influential factor when outcome is evaluated in surgical series $[1,22,27,31,32]$. It is clear that the number of aged patients is high among the untreated in this and other series. In our study, the difference in mean age in untreated and treated was 5 years, which is in the range of 3-6 years found in previous studies $[1,12,13,16]$. In our study, the age difference between men and women who were untreated was only 2 years, compared to the 5-year age

Table 3 Preoperative characteristics for treated and untreated, treatment and outcome variables for all included patients

\begin{tabular}{|c|c|c|c|}
\hline Variable & $\begin{array}{l}\text { Untreated } \\
N=71(25 \%)\end{array}$ & $\begin{array}{l}\text { Treated } \\
N=212(75 \%)\end{array}$ & $p$ \\
\hline Mean age (SD) years & $83.9(8.20)$ & $76.9(8.42)$ & $<0.001$ \\
\hline Women & $19(27)$ & $52(25)$ & 0.634 \\
\hline Previously detected & $35(49)$ & $50(24)$ & $<0.001$ \\
\hline Hypertension & $42(59)$ & $133(63)$ & 0.818 \\
\hline Heart disease & $30(42)$ & $72(34)$ & 0.444 \\
\hline Diabetes & $5(7)$ & $30(14)$ & 0.276 \\
\hline COPD & $11(15)$ & $31(15)$ & 0.967 \\
\hline Blood pressure, lowest registered ${ }^{\mathrm{a}}$ & $67.87(45.51)$ & $80.58(41.68)$ & 0.074 \\
\hline
\end{tabular}

Presented as numbers (\%) and mean (standard deviation)

${ }^{\text {a }}$ Missing cases, in analysis; 19 untreated and 30 treated 
Table 4 Previous publications on numbers and outcome for untreated and treated patients admitted with rAAA

\begin{tabular}{|c|c|c|c|c|}
\hline Author Time period & $\begin{array}{l}\text { Number of patients } \\
\text { admitted }\end{array}$ & Untreated & Mortality all & Mortality treated \\
\hline $\begin{array}{l}\text { Bengtsson et al. } \\
\quad(1971-1986)\end{array}$ & 125 & $51 \%$ & $79 \%$ (30 days) & $57 \%$ \\
\hline McPhee (2001-2004) & 37,016 & $\begin{array}{l}32 \%(41 \% \text { women vs } 30 \% \\
\text { men) }\end{array}$ & Not reported & $\begin{array}{l}37 \%(43 \% \text { women vs } 36 \% \\
\text { men) })^{\mathrm{b}}\end{array}$ \\
\hline Ozdemir (2005-2010) & 9877 & $42 \%$ & $\begin{array}{l}67.5 \% \\
\quad(90 \text { days })\end{array}$ & $44 \%$ (90 days) \\
\hline Vännia (2001-2011) & 354 & $26 \%$ (134 nonadmitted) & $71 \%$ & $43 \%$ treated \\
\hline Reite (2000-2013) & $196(216)$ & $26 \%$ & $64 \%$ (30 days) & $51 \%$ (90 days) \\
\hline Hultgren (2009-2013) & 280 & $25 \%$ & $53 \%$ (30 days) & $38 \%$ (30 days) \\
\hline
\end{tabular}

a 134 died outside hospital (27\%)

b In-hospital

difference in treated, which implies that age is an important factor when the decision to operate or not is made, more than gender.

During the study period, a shift in the care of patients was performed in the County, and an "EVAR first strategy" was developed, which have been reported by others [2-4, 23, 27]. This started in 2010-2011, and specific analysis has therefore not been analyzed in detail. The operation rates for AAA overall have increased for both men and women since the 1970s [1, 3, 13, 16]. During the period from 1971 to 1986 , operation rates were reported to be $28 \%$ for women and $56 \%$ for men [29]. Populationbased retrospective studies have showed that a lower proportion of women than men with rAAA are operated $[13,16]$. The operation rate for women in our study is, however, high and corresponds well to other contemporary reports (Reite $22 \%$, Dalman $26 \%$ ) [9, 23]. This indicates a shift in the care of rAAA patients and will also increase the mean age in treated (Fig. 3). One can suspect that the increasing number of screened men (which started in the fall 2010) will affect the proportion of treated women with rupture, since the number of men with rupture will decrease in the future $[8,33]$. The screening program has not yet affected the rupture rate in the general population in our region, so findings from this report should still be applicable to populations without general screening.

The number of elderly patients treated with EVAR is clearly shown in this material, which confirms other reports, both registry based and single centers. The case mix makes all comparisons on outcome difficult between OR and EVAR patients; the EVAR-treated patients are older, but obviously have a different morphology with smaller aneurysms, and require less ICU and hospital stay, as has been shown by others $[12,21,23]$.

The Swedvasc annual report 2014 showed that the total proportion of rAAA operations conducted with EVAR in
Sweden was $39 \%$ in 2013 [3]. In our study, the total rate of EVAR among operated patients (men and women) during the 5-year period was $27 \%$, with more performed in the latter period. The largest randomized trial comparing EVAR first strategy versus OR first for rAAA found that women have greater survival benefit from EVAR relatively to OR than men [26].

The outcome in a rAAA must always include reflections upon the number of treated versus untreated, since a high intervention rate will give a poorer survival rate and a lower intervention rate gives a better survival rate due to the selection bias. This is difficult to control, and mean age is a possible surrogate variable for such a biased inclusion. Our study includes all patients with rAAA admitted to hospital, but does not tell us about the number of deaths from rAAA outside of hospital. The in-hospital mortality from rAAA has declined since the 1980s, partly due to the introduction of EVAR [1, 16, 30], but there is no reason to believe that the mortality from rAAA outside of hospital has declined. Bengtsson et al. [29] performed a retrospective study in Malmö, including operated patients who died in hospital and outside of hospital (autopsy rate $85 \%$ ). Their poorer outcome compared to reported contemporary data from us and others could reflect a higher awareness today when referring rAAA patients, increased willingness to treat even old patients with comorbidity and possibly the increased use of EVAR (Table 4).

Postoperative mortality has been reported to be higher for women than for men in several previous studies, even if contradictory findings have been reported after age adjustments [5, 12, 13, 16, 21, 31]. In our study, and others, 30-day crude mortality was almost identical between all men and women regardless of the age difference $[9,14,31]$. The reasons mentioned above are probably highly applicable for both women and men. 


\section{Strengths and limitations}

The included patients in this study represent a fifth of all admitted persons with rAAA in Sweden. In an international comparison, this is a large material for this type of study, considering the study period. As all retrospective studies, this study has its limitations as we rely on information partly collected in an acute care setting without research purposes, resulting in missing data. The results do harmonize well with other recent reports.

\section{Causes of death}

In Stockholm County, approximately 15,500 persons die annually (15-18\% of the total death rate in Sweden), and the death rate in Sweden is 87,000-90,000 annually. The autopsy rate in Sweden was only $11 \%$ in 2013, and in elderly women $6 \%$, the reliability of reported Causes of Deaths is therefore questionable [33]. A further extraction of reported deceased persons registered as rAAA at home, from central registries, would probably therefore not bring substantial information.

\section{Conclusions}

Our results and other contemporary series show a shift toward a higher rate of treated persons with rAAA, and improving outcomes for this patient group. The influence of EVAR as a "first-line" treatment modality does contribute to the improved outcome. In contrast to our hypothesis, female sex does not influence the treatment rates or outcome for rAAA patients, rather age is a factor that influences the willingness to treat patients with rAAA. Further analysis of radiological findings and postoperative complications to explain the positive transition in the care of this patient group are called for.

Acknowledgments We thank all colleagues and staff at all hospitals in Stockholm County and Gotland for their assistance in collecting data for this report.

Funding This study was supported by the Swedish Heart-Lung Foundation, and by the regional agreement on medical training and clinical research (ALF) between Stockholm County Council and the Karolinska Institute. The Royal Institute of Technology and Karolinska Institute combined funding "Health, medicine and Technology" also supported this project.

Author contribution RH, JR and SZ contributed to study design. MG and SZ contributed to data collection. MG, SZ and RH contributed to data analysis. SZ, RH and JR contributed to data interpretation. RH wrote the manuscript. SZ, RH, JR and MG critically revised the manuscript.

\section{Compliance with ethical standards}

Conflicts of interest None.
Open Access This article is distributed under the terms of the Creative Commons Attribution 4.0 International License (http://crea tivecommons.org/licenses/by/4.0/), which permits unrestricted use, distribution, and reproduction in any medium, provided you give appropriate credit to the original author(s) and the source, provide a link to the Creative Commons license, and indicate if changes were made.

\section{References}

1. Larsson E, Granath F, Swedenborg J et al (2008) More patients are treated for nonruptured abdominal aortic aneurysms, but the proportion of women remains unchanged. J Vasc Surg 48(4):802-807

2. Ozdemir BA, Karthikesalingam A, Sinha S et al (2015) Association of hospital structures with mortality from ruptured abdominal aortic aneurysm. Br J Surg 102(5):516-524

3. Swedvasc (2015) Swedvasc. Annual report from the Swedish National vascular registry. In: SSVS U (ed.) http://www.ucr.uu. se/swedvasc/

4. Anjum A, von Allmen R, Greenhalgh R et al (2012) Explaining the decrease in mortality from abdominal aortic aneurysm rupture. Br J Surg 99(5):637-645

5. Mani K, Bjorck M, Lundkvist J et al (2009) Improved long-term survival after abdominal aortic aneurysm repair. Circulation 120(3):201-211

6. Linne A, Leander K, Lindstrom D et al (2014) Reasons for nonparticipation in population-based abdominal aortic aneurysm screening. Br J Surg 101(5):481-487

7. Adolfsson J, Hultgren R, Svensjö S, Wanhainen A (2015) National guidelines regarding screening of AAA in men, Nationella screeningprogram/bukaortaaneurysm. In: NBHW, Welfare SNBoHa, (eds.) http://www.socialstyrelsen.se/riktlinjer/natio nellascreeningprogram/bukaortaaneurysm, http://www.socialstyr elsen.se/publikationer2015/2015-11-34

8. Thompson SG, Ashton HA, Gao L et al (2012) Final follow-up of the Multicentre Aneurysm Screening Study (MASS) randomized trial of abdominal aortic aneurysm screening. Br J Surg 99(12): $1649-1656$

9. Reite A, Soreide K, Ellingsen CL et al (2015) Epidemiology of ruptured abdominal aortic aneurysms in a well-defined Norwegian population with trends in incidence, intervention rate, and mortality. J Vasc Surg 61(5):1168-1174

10. Vanni V, Turtiainen J, Hakala T et al (2016) Vascular comorbidities and demographics of patients with ruptured abdominal aortic aneurysms. Surgery 159(4):1191-1198. doi:10.1016/j.surg. 2015.10.005

11. van Beek SC, Vahl AC, Wisselink W et al (2015) Fate of patients unwilling or unsuitable to undergo surgical intervention for a ruptured abdominal aortic aneurysm. Eur J Vasc Endovasc Surg 49(2):163-165

12. Lo RC, Bensley RP, Hamdan AD et al (2013) Gender differences in abdominal aortic aneurysm presentation, repair, and mortality in the Vascular Study Group of New England. J Vasc Surg 57(5): $1261-1268$

13. McPhee JT, Hill JS, Eslami MH (2007) The impact of gender on presentation, therapy, and mortality of abdominal aortic aneurysm in the United States, 2001-2004. J Vasc Surg 45(5):891-899

14. Skibba AA, Evans JR, Hopkins SP et al (2015) Reconsidering gender relative to risk of rupture in the contemporary management of abdominal aortic aneurysms. J Vasc Surg 62(6):1429-1436

15. Hultgren R, Vishnevskaya L, Wahlgren CM (2013) Women with abdominal aortic aneurysms have more extensive aortic neck pathology. Ann Vasc Surg 27(5):547-552 
16. Mureebe L, Egorova N, McKinsey JF et al (2010) Gender trends in the repair of ruptured abdominal aortic aneurysms and outcomes. J Vasc Surg 51(4 Suppl):9S-13S

17. Semmens JB, Norman PE, Lawrence-Brown MM et al (2000) Influence of gender on outcome from ruptured abdominal aortic aneurysm. Br J Surg 87(2):191-194

18. Brahmbhatt R, Gander J, Duwayri Y et al (2016) Improved trends in patient survival and decreased major complications after emergency ruptured abdominal aortic aneurysm repair. J Vasc Surg 63(1):39-48

19. Hultgren R, Granath F, Swedenborg J (2007) Different disease profiles for women and men with abdominal aortic aneurysms. Eur J Vasc Endovasc Surg 33(5):556-560

20. Khashram M, Williman JA, Hider PN et al (2016) Systematic review and meta-analysis of factors influencing survival following abdominal aortic aneurysm repair. Eur J Vasc Endovasc Surg 51(2):203-215. doi:10.1016/j.ejvs.2015.09.007

21. Mehta M, Byrne WJ, Robinson $\mathrm{H}$ et al (2012) Women derive less benefit from elective endovascular aneurysm repair than men. J Vasc Surg 55(4):906-913

22. de Leur K, Flu HC, Ho GH et al (2015) Outcome of elective treatment of abdominal aortic aneurysm in elderly patients. Int $\mathbf{J}$ Surg 15:117-123

23. Ullery BW, Tran K, Chandra V et al (2015) Association of an endovascular-first protocol for ruptured abdominal aortic aneurysms with survival and discharge disposition. JAMA Surg 150(11):1058-1065

24. Egorova NN, Vouyouka AG, McKinsey JF et al (2011) Effect of gender on long-term survival after abdominal aortic aneurysm repair based on results from the Medicare national database. J Vasc Surg 54(1):1-12 discussion 11-2
25. Sweeting MJ, Balm R, Desgranges $P$ et al (2015) Individualpatient meta-analysis of three randomized trials comparing endovascular versus open repair for ruptured abdominal aortic aneurysm. Br J Surg 102(10):1229-1239

26. Investigators IT, Powell JT, Sweeting MJ et al (2014) Endovascular or open repair strategy for ruptured abdominal aortic aneurysm: 30 day outcomes from IMPROVE randomised trial. BMJ 348:f7661

27. Ali MM, Flahive J, Schanzer A et al (2015) In patients stratified by preoperative risk, endovascular repair of ruptured abdominal aortic aneurysms has a lower in-hospital mortality and morbidity than open repair. J Vasc Surg 61(6):1399-1407

28. von Elm E, Altman DG, Egger M et al (2008) The strengthening the reporting of observational studies in epidemiology (STROBE) statement: guidelines for reporting observational studies. J Clin Epidemiol 61(4):344-349

29. Bengtsson H, Bergqvist D (1993) Ruptured abdominal aortic aneurysm: a population-based study. J Vasc Surg 18(1):74-80

30. Bastos Goncalves F, Ultee KH, Hoeks SE et al (2015) Life expectancy and causes of death after repair of intact and ruptured abdominal aortic aneurysms. J Vasc Surg (e-pub)

31. Alexander S, Bosch JL, Hendriks JM et al (2008) The 30-day mortality of ruptured abdominal aortic aneurysms: influence of gender, age, diameter and comorbidities. J Cardiovasc Surg 49(5):633-637

32. Allen CJ, Hannay WM, Murray CR et al (2015) Causes of death differ between elderly and adult falls. J Trauma Acute Care Surg 79(4):617-621

33. Swedish NBHW (Socialstyrelsen) (2014) Causes of death 2013. Secondary Causes of death 2013 